\title{
Investigating the Role of Subglottic Secretions Suctioning in the Prevention of Ventilator Associated Pneumonia in Patients With Invasive Mechanical Ventilation
}

\author{
Iyad Abbas Salman ${ }^{1}$, Waleed Ibraheem $\mathrm{Ali}^{2}$, Amir Ibrahim Moushib ${ }^{3} \&$ Hayder Adnan Fawzi ${ }^{4}$ \\ ${ }^{1}$ Assistant Professor, Consultant Anesthetist, Baghdad Medical College, Iraq \\ ${ }^{2}$ Lecturer, Internist, Bagdad Medical College, Iraq \\ ${ }^{3}$ Anesthetist, Department of Intensive Care, Ghazi Al-Hariri teaching Hospital, Baghdad Medical City Teaching \\ Complex, Baghdad, Iraq \\ ${ }^{4}$ Baghdad Medical City Teaching Complex, Clinical Pharmacy Department, Iraq \\ Correspondence: Hayder Adnan Fawzi, Baghdad Medical City Teaching Complex, Clinical Pharmacy \\ Department, Iraq. E-mail: Hayder.adnan2010@gmail.com
}

Received: February 28, 2019 Accepted: April 27, 2019 Online Published: May 8, 2019

doi:10.5539/gjhs.v11n6p111 URL: https://doi.org/10.5539/gjhs.v11n6p111

\begin{abstract}
Background: development of ventilator associated pneumonia (VAP) leads to prolonged hospital stay, increased health care cost, and mortality rates. Subglottic secretion drainage through a dedicated endotracheal tube has been advocated as a mean to decrease the incidence of VAP and thereby assisting in the decrease of morbidity associated with invasive mechanical ventilation.
\end{abstract}

Objective: Investigate the role of subglottic secretion suctioning in the prevention of VAP in mechanically ventilated patients in intensive care unit.

Methods: A cross sectional study done in the intensive care unit of Ghazi Al-Hariri hospital for surgical specialties in medical city complex, 30 patients who are in need for invasive mechanical ventilation were intubated with endotracheal tube that have special port for subglottic secretion suctioning. Daily monitoring of patients clinical and radiological data to detect features of VAP was done, and if there was a suspicion of pneumonia, culture for tracheal aspirate performed to confirm diagnosis.

Results: Patient's age was $37.1 \pm 15.39$ years, the highest proportion of study patients was found in age group $<30$ and 30-49 years (40\% in each group), most of the patients were males $(70 \%)$ with a male to female ratio of 2.33:1, Subglottic secretion suctioning lead to reduction in VAP by relative risk (95\%CI) of 0.167 (0.045-0.559), p-value $=0.001$. Twenty eight patients didn't show any sign, symptoms or radiological features suggesting a diagnosis of pneumonia while two patients developed features of pneumonia (suggestive signs and symptoms, radiological features and positive culture of tracheal aspirate).

Conclusion: the use of endotracheal tube with subglottic secretions suctioning can have a role in the prevention of VAP in mechanically ventilated patients.

Keywords: ventilator associated pneumonia, prevention, subglottic secretion suctioning

\section{Introduction}

Ventilator-associated pneumonia (VAP) is one of the most frequent hospital-acquired infections encountered in critically ill patients receiving mechanical ventilation. VAP is defined as pneumonia that develops 48 hours after patient been placed on mechanical ventilation. It is an important subset of hospital-acquired pneumonia (HAP), which occurs 48hours or longer after admission to the hospital and results from an infection that was not incubating at the time of admission (Kalanuria, Ziai, \& Mirski, 2014).

Ventilator-associated pneumonia is one of the most common nosocomial infections encountered in the intensive care unit (ICU) (Safdar, Dezfulian, Collard, \& Saint, 2005). It is estimated that the risk of development of VAP is about $3 \%$ per day during the 5 days of receiving mechanical ventilation, $2 \%$ per day for days 5 through and $1 \%$ thereafter. The incidence of VAP ranges from $20 \%$ to $28 \%$ for all intubated patients (Cook et al., 1998). The overall 
attributable mortality rate for VAP ranges from $5 \%$ to $48 \%$ depending on the infecting organism(s), underlying disease comorbidities, and prior antimicrobial therapy (Hunter, 2006).

\subsection{Pathogenesis of Ventilator-Associated Pneumonia}

The pathogenesis of VAP most often involves colonization of the aero-digestive tract with pathogenic bacteria, aspiration of contaminated secretions into the lower airways, followed by colonization of the normally sterile lower airways and lung parenchyma with these infectious microorganisms (Tejada Artigas et al., 2001).

During critical illnesses, particularly in patients with an endotracheal tube (ETT) and receiving mechanical ventilation, there is a dramatic shift in the flora of the oropharyngeal tract to gram-negative bacilli and $\mathrm{S}$. aurous (Safdar, Dezfulian, Collard, \& Saint, 2005). This shift in flora may be attributed to a number of factors that compromise host defense mechanisms including comorbidities, malnutrition, reduced levels of mucosal Immunoglobulin A, increased production of proteases, exposed and denuded mucous membranes, elevated airway $\mathrm{pH}$, and an increased number of airway receptors for bacteria as a result of acute illness and prior antimicrobial use (Safdar, Dezfulian, Collard, \& Saint, 2005; Levine \& Niederman, 1991).

Aspiration of the contaminated oropharyngeal secretions and in some cases, gastro-esophageal contents can occur because the patient is unable to protect the lower airways. Impaired level of consciousness, gastro-esophageal reflux, a blunted gag reflex, and abnormal swallowing can all contribute to the risk of aspiration. After these offending organisms penetrate and colonize the lower airways, they can overwhelm already compromised pulmonary cellular and humoral immune defense mechanisms and eventually lead to VAP (Tejada Artigas et al., 2001). The current work aimed to investigate the role of subglottic secretion suctioning in the prevention of VAP in mechanically ventilated patients in intensive care unit.

\subsection{Aspiration of Subglottic Secretions}

Secretions that pool around the ETT cuff are reservoirs of potentially pathogenic bacteria. Efforts to reduce silent aspiration of secretions above and below the ETT cuff have led to the development and use of specialized ETs. These specialized ETTs (see Figure 1) have a dorsal lumen above the ET cuff that allows for continuous or intermittent suction of tracheal secretions that accumulate above the patient's subglottic area (Mahul et al., 1992, Valles et al., 1995) (see Figure 1), aspiration of subglottic secretions has been shown to reduce the incidence of nosocomial pneumonias. Early studies reported that continuous aspiration of subglottic secretions reduced the incidence of VAP by nearly $50 \%$ (Valles et al., 1995). Studies also showed a five times greater likelihood of VAP when continuous aspiration of subglottic secretions was not used (Rello et al., 1996).

\section{Methods}

A cross sectional study done in the intensive care unit of Ghazi Al-Hariri teaching hospital in medical city complex, in the period from May 2017 to November 2017. Thirty patients admitted to the ICU who were in need for invasive mechanical ventilation intubated with a special endotracheal tube having a suction port for suctioning of subglottic (above the cuff) secretions (see Figure 1). The study was approved by scientific council of Anesthesia and Intensive care-Iraqi board, written inform consent taken from obtained from the patients (if the patient is conscious and awake) or their first of kin, this study done in accordance of Helsinki Declaration.

\subsection{Inclusion Criteria}

1) Adult patients (males \& females) admitted to ICU, with age above 14

2) Patients expected to need endotracheal intubation \& mechanical ventilation for more than 48 hours

\subsection{Exclusion Criteria}

1) Patients already intubated with regular endotracheal tube for more than 48 hours

2) Patients with tracheostomy tube

3) Patients with extra pulmonary infection or sepsis.

\subsection{Procedure}

Candidate patients were intubated with this special tube with instructions for regular (every two hours) suctioning. The insertion of the tube was done according to local ICU guidelines using laryngoscope and induction agents (hypnotics \pm analgesics \pm muscle relaxants), the cuff of the tube was inflated with air. VAP care bundle which include raising the head of the bed 30 to 45 degrees, mouth care, prophylaxis of peptic ulcer, daily sedation breaks was applied to all patients under study. 


\subsection{Data Collection}

Clinical data including daily record of patients pulse rate, blood pressure, temperature; radiological features of VAP (new infiltration, progression of already present infiltration or new pleural effusion); oxygenation status of the patient (FIO2, PEEP, P/F ratio). The presence or absence of purulent secretions all were collected using pre-constructed form sheet (see Figure S1).

Data collection was continued as long as the patient remains intubated and this was determined by several factors including: need for extubation, replacement of endotracheal tube with tracheostomy tube, death of the patient, referral of the patient, and patient develop VAP.

Occurrence of VAP was monitored daily by observing patient clinical data (fever, danleukocytosis) and radiological investigations $\&$ if there was a suspicion of pneumonia, tracheal aspirate was obtained and sent for microbiological examination

Criteria used for diagnosing VAP include (Kalanuria, Ziai, \& Mirski, 2014):

1) Presence of suggestive signs and symptoms (fever, leukocytosis, and purulent secretions)

2) Presence of suggestive radiological signs

3) Presence of growth in the culture of tracheal aspirate

\subsection{Statistical Analysis}

Independent $\mathrm{t}$-test used to compare the men between two groups, in order to assess the risk reduction of using subglottic secretions to reduce the risk of VAP we compare the 30 patients with 60 patients from our ICU ward (historical cohort, with VAP rate of $40 \%$ ), that the Relative risk was calculated and its $95 \% \mathrm{CI}$ of relative risk was calculated using the Koopman asymptotic score method (Bedrick, 1987), level of significant $<0.005$ was considered to be significant.

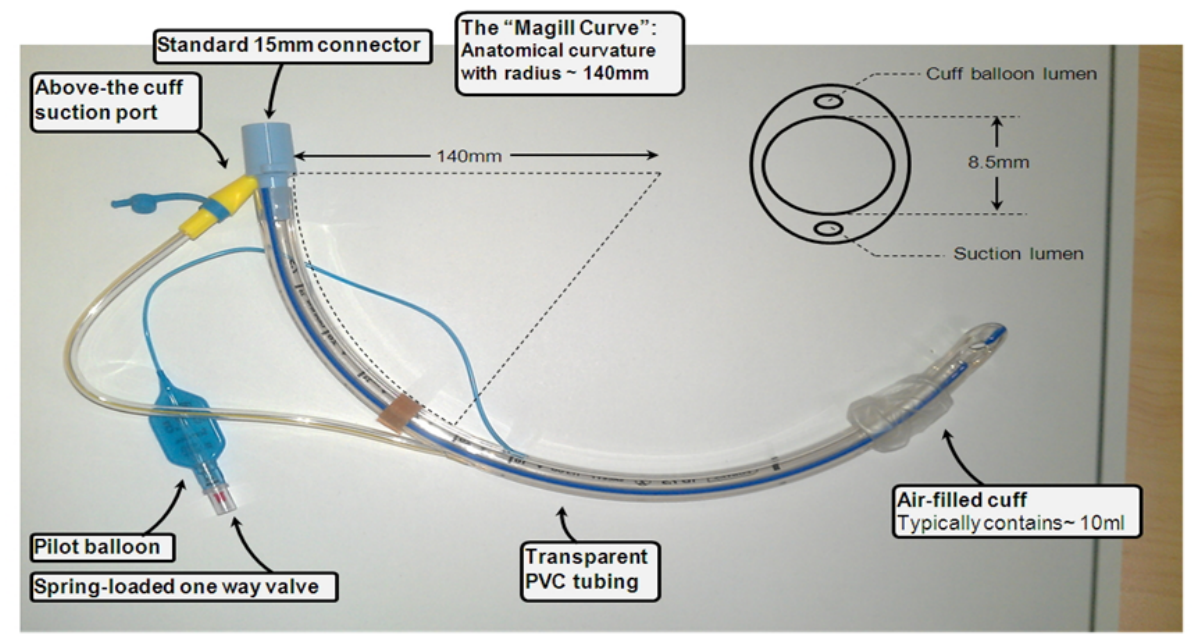

Figure 1. Endotracheal tube dedicated for subglottic secretions suctioning (SSS)

\section{Results}

The distribution of study patients by general characteristics is shown in table (1). Study patient's age was ranging from 22 to 78 years with a mean of 37.1 years and standard deviation (SD) of \pm 15.39 years. The highest proportion of study patients was found in age group $<30$ and 30 - 49 years ( $40 \%$ in each group). Regarding gender, most of the patients were males $(70 \%)$ with a male to female ratio of $2.33: 1$, the rest of clinical characteristics are illustrated in Table 1 and Figure 2.

The use of subglottic suction lead to reduction of risk of VAP (ARR: $1.0-0.167=0.833$, i.e. $83.3 \%$ reduction in risk after using subglottic suction instead of standard of care), as illustrated in Table 2. 
Table 1. Assessment of demographic and clinical characteristics of patients

\begin{tabular}{|c|c|}
\hline Variables & Value \\
\hline Number & 30 \\
\hline \multicolumn{2}{|l|}{ Age (years), n (\%) } \\
\hline$<30$ & $12(40 \%)$ \\
\hline $30-49$ & $12(40 \%)$ \\
\hline$\geq 50$ & $6(20 \%)$ \\
\hline \multicolumn{2}{|l|}{ Gender, $\mathrm{n}(\%)$} \\
\hline Female & $21(70 \%)$ \\
\hline Male & $9(30 \%)$ \\
\hline \multicolumn{2}{|l|}{ Cause Of Intubation, n (\%) } \\
\hline Respiratory failure & $11(36.7 \%)$ \\
\hline Sedation and IPPV & $2(6.7 \%)$ \\
\hline Loss of consciousness & $16(53.3 \%)$ \\
\hline Upper Airway Obstruction & $1(3.3 \%)$ \\
\hline \multicolumn{2}{|l|}{ Diagnosis, $\mathrm{n}(\%)$} \\
\hline Guillain-Barré syndrome & $3(10.0 \%)$ \\
\hline Tetanus & $6(20.0 \%)$ \\
\hline Chest trauma & $2(6.7 \%)$ \\
\hline Cervical Spine trauma & $2(6.7 \%)$ \\
\hline Traumatic Brain Injury & $8(26.7 \%)$ \\
\hline Multiple injury & $4(13.3 \%)$ \\
\hline Drug Poisoning & $2(6.7 \%)$ \\
\hline Carcinoma with Brain Metastasis & $1(3.3 \%)$ \\
\hline Liver Failure & $1(3.3 \%)$ \\
\hline Cancer of Larynx & $1(3.3 \%)$ \\
\hline \multicolumn{2}{|l|}{ Duration of intubation (Days), $\mathrm{n}(\%)$} \\
\hline$<5$ & $9(30 \%)$ \\
\hline $5-7$ & $19(63.3 \%)$ \\
\hline$>7$ & $2(6.7 \%)$ \\
\hline Pneumonia, n (\%) & $2(6.7 \%)$ \\
\hline \multicolumn{2}{|l|}{ Outcome, n (\%) } \\
\hline Tracheostomy & $14(46.7 \%)$ \\
\hline Extubation & $10(33.3 \%)$ \\
\hline Death & $6(20 \%)$ \\
\hline
\end{tabular}




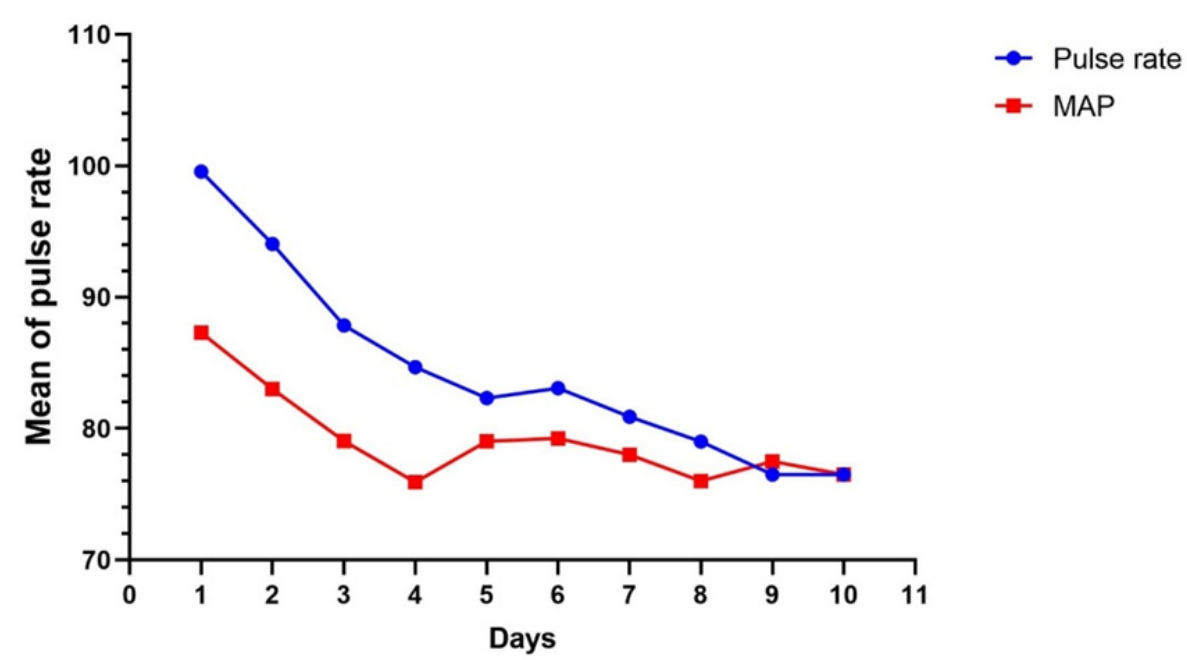

Figure 2. Change in pulse rate and MAP during the first ten days of admission

Table 2. Relationship between subglottic suction and risk reduction of VAP

\begin{tabular}{lllll}
\hline & Subglottic suction & Standard of care & RR (95\%CI) & p-value \\
\hline VAP & $2(6.7 \%)$ & $24(40 \%)$ & $0.167(0.045-0.559)$ & 0.001 \\
No VAP & $28(93.3 \%)$ & $36(60 \%)$ & & \\
\hline
\end{tabular}

VAP: ventilator associated pneumonia, RR: relative risk, CI: confidence interval.

\section{Discussion}

Nosocomial infections is a big issue for patients because of increased morbidity and mortality, especially VAP (Stevens, Teres, Skillman, \& Feingold, 1974). Several studies have shown that pooled secretions above inflated endotracheal tube cuffs can be the cause of VAP and aspiration of these secretions by intermittent suctioning can influence the incidence of pneumonia (Greene et al., 1994).

The current study showed that from the 30 patients enrolled, 28 patients and this translated into $93.3 \%$ did not develop VAP as long as they were intubated with this special tube that incorporate suction port for SSS. Whereas only 2 patients $(6.7 \%)$ developed VAP. Additionally the use of subglottic suction when compared to standard of care led to relative risk reduction [RR $(95 \% \mathrm{CI}): 0.167(0.045-0.559)]$. This finding goes with RCT done by Kees smudlers et al in a study involved 150 patients with an expected duration of mechanical ventilation (MV) more than 72 hours, 75 patients used SSD and 75 patients as control, VAP presented (4\%) receiving SSD and in (16\%) in the control group $(\mathrm{RR}[95 \% \mathrm{CI}]: 0.22[0.06$ to 0.81$] \mathrm{p}$-value $=0.014)$. They conclude that patients subjected to intermittent SSS had statistically Lower incidence of VAP with a reduction in risk by $75 \% \mathrm{p}$ value $=0.014$ (Smulders, van der Hoeven, Weers-Pothoff, \& Vandenbroucke-Grauls, 2002).

Walaszek et al. did analysis of medical records of patients receiving MV for more than 48 hours that were admitted to ICU between 2007 and 2014. There were 804 patients in the "no subglottic secretion drainage" (NSSD) group and 1003 patients in the "subglottic secretion drainage" (SSD) group. A difference was observed in VAP incidence frequency between both groups ( $\mathrm{p}$-value $<0.001$ ). In the NSSD group 86 VAP cases were reported (cumulative incidence 10.7\%), whereas in the SSD group, in which the tubes with subglottic secretion drainage were applied, there were only 43 VAP cases $(4.3 \%)$. The odds ratio (OR) was 2.5 , which meant that the probability of VAP cumulative incidence was higher in NSSD group and found that the use of ETT with SSS significantly reduced the incidence of VAP (Walaszek, Gniadek, Kolpa, Wolak, \& Kosiarska, 2017).

Muscedere et al. did a meta-analysis of 13 RCT 12 of them reported a reduction in VAP in patients with SSS. They identified 13 randomized clinical trials that met the inclusion criteria with a total of 2442 randomized patients. Of the 13 studies, 12 reported a reduction in VAP rates in the subglottic secretion drainage group; in meta-analysis, the overall risk ratio for VAP was $0.55(95 \%$ confidence interval, $0.46-0.66$; p-value $<0.001)$ and concluded that in those patients at risk of VAP using ETT with SSS is effective for the prevention of VAP \& also May be associated 
with decreased use of MV \& ICU length of stay (Muscedere et al., 2011).

Lacherade et al. did RCT that conducted at four French centers, in this study $14.8 \%$ of the patients using SSD had VAP and 25.6\% had VAP in the control group [P-value $=0.02$ ], the RRR was $42.2 \%$ (95\% CI: 10.4-63.1\%).

VAP benefit was observed in both early-onset VAP [1.2\%] patients undergoing SSD vs. [6.1\%] control patients) and late-onset VAP [18.6\%] patients undergoing SSD vs. [33.0\%] control patients), and thus found a marked decrease in the incidence of microbiological confirmed VAP with the use of SSS, but secondary outcomes like decrease in mortality and duration of MV were not influenced (Lacherade et al., 2010). On the other hand, Ghoochani khorasani et al compare the incidence of VAP in severely ill poisoned patients who are intubated using ETT with SSS versus conventional ETT and in this clinical randomized trial, 91 eligible patients with an expected duration of mechanical ventilation of more than 48 hours were recruited and randomly assigned into two groups: (1) subglottic secretion drainage (SSD) group who were intubated by SSS ETT $(n=43)$ and (2) control group who were intubated by Convential ETT $(n=48)$. Of the 91 eligible patients, VAP was detected in 24 of $43(55.8 \%)$ patients in the SSD group and 23 of $48(47.9 \%)$ patients in the control group $(P=0.45)$. The conclusion was that SSS Did not significantly decreases the incidence of VAP in patients receiving MV (Ghoochani Khorasani, Shadnia, Mashayekhian, Rahimi, \& Aghabiklooei, 2016). Also Jena et al., pilot study aiming to compare the incidence of VAP with standard ETT and suction above the cuff tube in neurologically ill patients and its impact on clinical outcome. In this study there was no significant difference in incidence of clinical and microbiological VAP seen between standard ETT and the one with SSS when other strategies for prevention of VAP were similar (Jena et al., 2016).

\section{Conclusion}

The use of endotracheal tube with subglottic secretions suctioning can have a role in the prevention of VAP in mechanically ventilated patients.

\section{Acknowledgments}

We the authors extend their thanks for the medical staff in Baghdad Medical city for their help in completing this work.

\section{Competing Interests Statement}

The authors declare that there are no competing or potential conflicts of interest.

\section{References}

Bedrick, E. J. (1987). A family of confidence intervals for the ratio of two binomial proportions. Biometrics, 43, 993-8. https://doi.org/10.2307/2531551

Cook, D. J., Walter, S. D., Cook, R. J., Griffith, L. E., Guyatt, G. H., Leasa, D., Jaeschke, R. Z., \& Brun-Buisson, C. 1998. Incidence of and risk factors for ventilator-associated pneumonia in critically ill patients. Ann Intern Med, 129, 433-40. https://doi.org/10.7326/0003-4819-129-6-199809150-00002

Ghoochani Khorasani, A., Shadnia, S., Mashayekhian, M., Rahimi, M., \& Aghabiklooei, A. (2016). Efficacy of Hi-Lo Evac Endotracheal Tube in Prevention of Ventilator-Associated Pneumonia in Mechanically Ventilated Poisoned Patients. Scientifica (Cairo), 2016, 4901026.https://doi.org/10.1155/2016/4901026

Greene, R., Thompson, S., Jantsch, H. S., Teplick, R., Cullen, D. J., Greene, E. M., ... \& Llewellyn, H. J. (1994). Detection of pooled secretions above endotracheal-tube cuffs: value of plain radiographs in sheep cadavers and patients. AJR Am J Roentgenol, 163, 1333-7. https://doi.org/10.2214/ajr.163.6.7992723

Hunter, J. D. (2006). Ventilator associated pneumonia. Postgrad Med J, 82, $172-8$. https://doi.org/10.1136/pgmj.2005.036905

Jena, S., Kamath, S., Masapu, D., Veenakumari, H. B., Ramesh, V. J., Bhadrinarayan, V., \& Ravikumar, R. (2016). Comparison of suction above cuff and standard endotracheal tubes in neurological patients for the incidence of ventilator-associated pneumonia and in-hospital outcome: A randomized controlled pilot study. Indian $J$ Crit Care Med, 20, 261-6. https://doi.org/10.4103/0972-5229.182196

Kalanuria, A. A., Ziai, W., \& Mirski, M. (2014). Ventilator-associated pneumonia in the ICU. Crit Care, $18,208$. https://doi.org/10.1186/cc13775

Lacherade, J. C., De Jonghe, B., Guezennec, P., Debbat, K., Hayon, J., Monsel, A., ... \& Bastuji-Garin, S. (2010). Intermittent subglottic secretion drainage and ventilator-associated pneumonia: a multicenter trial. $\mathrm{Am} \mathrm{J}$ Respir Crit Care Med, 182, 910-7. https://doi.org/10.1164/rccm.200906-0838OC 
Levine, S. A., \& Niederman, M. S. (1991). The impact of tracheal intubation on host defenses and risks for nosocomial pneumonia. Clin Chest Med, 12, 523-43.

Mahul, P., Auboyer, C., Jospe, R., Ros, A., Guerin, C., El Khouri, Z., Galliez, M., Dumont, A., \& Gaudin, O. (1992). Prevention of nosocomial pneumonia in intubated patients: respective role of mechanical subglottic secretions drainage and stress ulcer prophylaxis. Intensive Care Med, 18, 20-5. https://doi.org/10.1007/BF01706421

Muscedere, J., Rewa, O., Mckechnie, K., Jiang, X., Laporta, D., \& Heyland, D. K. (2011). Subglottic secretion drainage for the prevention of ventilator-associated pneumonia: a systematic review and meta-analysis. Crit Care Med, 39, 1985-91.https://doi.org/10.1097/CCM.0b013e318218a4d9

Rello, J., Sonora, R., Jubert, P., Artigas, A., Rue, M., \& Valles, J. (1996). Pneumonia in intubated patients: role of respiratory airway care. Am $J$ Respir Crit Care Med, 154, 111-5. https://doi.org/10.1164/ajrccm.154.1.8680665

Safdar, N., Dezfulian, C., Collard, H. R., \& Saint, S. (2005). Clinical and economic consequences of ventilator-associated pneumonia: a systematic review. Crit Care Med, 33, 2184-93. https://doi.org/10.1097/01.CCM.0000181731.53912.D9

Smulders, K., Van Der Hoeven, H., Weers-Pothoff, I., \& Vandenbroucke-Grauls, C. (2002). A randomized clinical trial of intermittent subglottic secretion drainage in patients receiving mechanical ventilation. Chest, 121, 858-62. https://doi.org/10.1378/chest.121.3.858

Stevens, R. M., Teres, D., Skillman, J. J., \& Feingold, D. S. (1974). Pneumonia in an intensive care unit. A 30-month experience. Arch Intern Med, 134, 106-11. https://doi.org/10.1001/archinte.1974.00320190108015

Tejada Artigas, A., Bello Dronda, S., Chacon Valles, E., Munoz Marco, J., Villuendas Uson, M. C., Figueras, P., Suarez, F. J., \& Hernandez, A. (2001). Risk factors for nosocomial pneumonia in critically ill trauma patients. Crit Care Med, 29, 304-9. https://doi.org/10.1097/00003246-200102000-00015

Valles, J., Artigas, A., Rello, J., Bonsoms, N., Fontanals, D., Blanch, L., Fernandez, R., Baigorri, F., \& Mestre, J. (1995). Continuous aspiration of subglottic secretions in preventing ventilator-associated pneumonia. Ann Intern Med, 122, 179-86. https://doi.org/10.7326/0003-4819-122-3-199502010-00004

Walaszek, M., Gniadek, A., Kolpa, M., Wolak, Z., \& Kosiarska, A. (2017). The effect of subglottic secretion drainage on the incidence of ventilator associated pneumonia. Biomed Pap Med Fac Univ Palacky Olomouc Czech Repub, 161, 374-380. https://doi.org/10.5507/bp.2017.041

\section{Copyrights}

Copyright for this article is retained by the author(s), with first publication rights granted to the journal.

This is an open-access article distributed under the terms and conditions of the Creative Commons Attribution license (http://creativecommons.org/licenses/by/4.0/). 